\title{
Use of compounded dispersing media for extemporaneous pediatric syrups with candesartan cilexetil and valsartan
}

MONIKA MUSKO $1,2, *$

MALGORZATA SZNITOWSKA ${ }^{3}$

${ }^{1}$ Department of Pharmaceutical

Technology, Medical University of

Bialystok, Faculty of Pharmacy

Bialystok, Poland

${ }^{2}$ Department of Clinical Pharmacy Medical University of Bialystok Faculty of Pharmacy, Bialystok, Poland

${ }^{3}$ Department of Pharmaceutical Technology, Medical University of Gdansk, Faculty of Pharmacy

Gdansk, Poland
Accepted July 8, 2014

\begin{abstract}
Available tablets or capsules for adults are often used to prepare extemporaneously formulated medicines appropriate for children. The most acceptable drug forms in pediatric population are oral liquids and pharmacists use commercial dispersing media to compound syrups from an active substance or from tablets available on the market. In many countries ready-to-use dispersing media are not available or refunded, but pharmacists can use other compounded media, providing their compatibility and stability are proven. The aim of this study was to formulate and evaluate the stability of syrups with candesartan cilexetil (1 $\left.\mathrm{mg} \mathrm{mL}^{-1}\right)$ and valsartan $\left(4 \mathrm{mg} \mathrm{mL}^{-1}\right)$ extemporaneously prepared using commercial tablets (Diovan ${ }^{\circledR}$ and Atacand ${ }^{\circledR}$ ). The following three different suspending media, which could be easily made in a pharmacy, were investigated: V1 - with xanthan gum (0.5\%), V2 - the USP/NF vehicle for oral solution and V3 - the medium based on a simple sucrose syrup. The stability of preparations was studied during 35 days of storage in a dark place at controlled temperature of 25 and $4{ }^{\circ} \mathrm{C}$. During the study, microscopic observation was carried out and $\mathrm{pH}$, viscosity, and concentration of candesartan cilexetil and valsartan were analyzed. Syrups with valsartan prepared with V2 and V3 media were stable for 3 or 4 weeks when stored at $25^{\circ} \mathrm{C}$, while syrups with candesartan were stable for as long as 35 days. For syrups prepared using V1 medium, the 14-day expiry date was not achieved because of microbial deterioration.
\end{abstract}

Keywords: extemporaneous formulation, pediatric syrups, candesartan cilexetil, valsartan, stability

Abbreviations: CAN - candesartan cilexetil; VAL - valsartan; V1 - suspending medium with xanthan gum; V2 - suspending medium prepared according to the US Pharmacopoeia »Vehicle for oral solution «(USP/NF 36/31); V3 - suspending medium based on a simple sucrose syrup.

\footnotetext{
*Corresponding author: monikam@umb.edu.pl
} 
There is growing concern in clinical practice about the suitability of medicines for children - administration of proper doses and formulations. According to the number of PIP applications (Pediatric Investigation Plan) approved by EMA (European Medicines Agency), cardiovascular diseases rank seventh among the 17 various therapeutic areas regarded as most prevalent in the pediatric population (1). Aside from the abnormalities of heart rhythms, hypertension is quite common in the pediatric population, since it can develop in childhood. Hypertension in children is developed as a secondary disease, rooted in another medical condition (especially in pre-adolescence) or, as in the case of adults, being the result of such factors as, e.g., overweight or lack of exercise. Accessibility of the pediatric population to appropriate cardiovascular medicines is still low. Although over recent years, ever more drugs used in cardiovascular diseases are granted pediatric licenses (e.g., captopril, enalapril, amlodipine), one can still encounter medicines used off-label, which are registered for adults only or do not have an appropriate pediatric pharmaceutical form. If an appropriate pediatric dosage form or a dose is unavailable, medicines for adults have to be adjusted by splitting or crushing tablets. An appropriate dose is often obtained when extemporaneous powders are prepared by pharmacists.

Liquid extemporaneous pediatric forms are more common in North America, United Kingdom, Portugal, Spain, whereas powders are often prepared in Eastern Europe $(2,3)$. Although syrups are a better application form, it is necessary to conduct stability studies even for short-time storage and careful selection of the suspending medium is obligatory. Stability should be confirmed separately for each combination of brand tablet/capsule and suspending medium, since different interactions are possible not only with water but also with other additives.

Although candesartan cilexetil (CAN) and valsartan (VAL) belong to the antihypertensive drugs most commonly used in the pediatric population, their liquid dosage forms are not available. Both drugs are angiotensin II receptor antagonists. They could be used in monotherapy or in the combination with other antihypertensive drugs, as indicated in prescribing information of Atacand ${ }^{\circledR}$ and Diovan ${ }^{\circledR}$ products (4-7) and in the literature (8-11).

Candesartan cilexetil is available in the form of uncoated 4, 8, 16 and $32 \mathrm{mg}$ strength tablets and is used in the treatment of adults and children from 1 to 17 years of age. For children below 6 years of age, the daily dose range is 0.05 to $0.4 \mathrm{mg} \mathrm{kg}^{-1}$, applied once daily or divided into two equal doses (5). The tablets, however, are not suitable for small children, who are unable to swallow tablets or capsules. Valsartan (VAL) is available in tablets containing 40,80,160 or $320 \mathrm{mg}$ of active substance. VAL is registered for the treatment of hypertension in children from 6-18 years of age with a starting dose of $1.3 \mathrm{mg} / \mathrm{kg}$, administered once daily. The dose can be increased to a maximum daily dose of $40 \mathrm{mg}$. Although the safety and efficacy of CAN and VAL were confirmed by Schaefer et al. $(12,13)$ in children aged 12 and 6 months, respectively, the use of VAL in children younger than 6 years is still an off-label practice.

VAL and CAN are rare examples of tablets that can be used for the preparation of pediatric oral liquids as »industry-verified preparations «. This term means that oral liquids would be prepared from marketed tablets or capsules employing a method provided by the manufacturer in the product leaflet, well-defined and verified, guaranteeing stability and dose uniformity of the syrup (14). Astra Zeneca, the manufacturer of tablets with CAN (Atacand ${ }^{\circledR}$ ), recommends in its drug information leaflets that syrup can be prepared by a pharmacist from the tablets using as a suspending liquid a mixture of Ora-Plus ${ }^{\circledR}$ and 
sugar-free Ora-Sweet $\mathrm{SF}^{\circledR}(1: 1)$ or a sugar-free Ora-Blend $\mathrm{SF}^{\circledR}$ vehicle. The former suspending medium is proposed by Novartis, the manufacturer of Diovan ${ }^{\circledR}$ (VAL tablets), for preparing a pediatric »industry verified liquid « from these tablets.

Ora ${ }^{\circledR}$ products (Ora-Sweet ${ }^{\circledR}$, Ora-Sweet $\mathrm{SF}^{\circledR}$, , Ora-Plus $^{\circledR}$, , Ora-Blend $^{\circledR}$, Ora-Blend $\mathrm{SF}^{\circledR}$ ) are aqueous syrups, sweetened and flavored (except for Ora-Plus ${ }^{\circledR}$ ). They are used to simplify compounding of extemporaneous oral suspensions and syrups. The Ora-Plus ${ }^{\circledR}$ and OraBlend $^{\circledR}$ contain suspending agents (microcrystalline cellulose, carboxymethylcellulose sodium, xanthan gum, carrageen) forming colloidal solutions and preventing the powdered tablet mass to settle. They are preserved with methylparaben and potassium sorbate and phosphate buffer allows maintenance of a slightly acidic $\mathrm{pH}$. Ora-Plus ${ }^{\circledR}$, as a non-flavored vehicle, could be combined with Ora-Sweet ${ }^{\circledR}$ to produce a pleasant taste of the suspension (15).

Suspension with Atacand ${ }^{\circledR}$ tablets can be prepared in a CAN concentration within the range of 0.1 to $2.0 \mathrm{mg} \mathrm{mL}^{-1}$, but the most commonly recommended concentration is $1 \mathrm{mg}$ $\mathrm{mL}^{-1}$. The suspension should be stored in an amber polyethylene bottle at room temperature and used within 30 days after the first opening (5). Suspensions at a concentration of $4 \mathrm{mg}$ $\mathrm{mL}^{-1}$ VAL are obtained by simply disintegrating the tablets in a vehicle while shaking them in the final container. The prepared suspension remains stable for 30 days when stored at room temperature or up to 75 days under refrigerated conditions (7).

In some countries, the availability of Ora ${ }^{\circledR}$ suspending media (Perrigo Company plc, Ireland) is limited and, moreover, the final cost of the prepared extemporaneous syrups is high due to legal regulations in force, which do not allow the refunding of preparations made of components not registered for pharmaceutical use (commercial suspending media are not registered as such). It is, therefore, necessary to use simple suspending vehicles in syrups that could be prepared in a pharmacy from components registered for pharmaceutical use. Such compositions are provided in the literature $(16,17)$. The USP/NF Pharmacopoeia (17) contains formulas for preparing vehicles for oral solutions or suspensions as well as other flavoring syrups (e.g., Sugar-Free Suspension Structured Vehicle, Vehicle for Oral Solution, Vehicle for Oral Suspension, and Raspberry Syrup, Cherry Syrup, Chocolate Syrup or Orange Syrup).

The aim of this study was to develop and assess the stability of extemporaneous syrups with CAN or VAL prepared with simple suspending media compounded in a pharmacy. The developed syrups, prepared in pediatric doses from commercially available tablets with three different media, were analyzed and the expiry date was proposed.

\section{EXPERIMENTAL}

\section{Chemicals and reagents}

Tablets for syrup preparation were obtained from a local pharmacy: Atacand ${ }^{\circledR}$ (Astra Zeneca $\mathrm{AB}$, Sweden), containing $16 \mathrm{mg}$ of candesartan cilexetil and Diovan ${ }^{\circledR}$ (Novartis, Germany) with $160 \mathrm{mg}$ of valsartan. Atacand ${ }^{\circledR}$ tablets are uncoated and contain the following excipients: calcium salt of carboxymethylcellulose, hydroxypropylcellulose, lactose monohydrate, magnesium stearate, corn starch, polyethylene glycol 8000, iron oxides. Dio$\operatorname{van}^{\circledR}$ coated tablet (taste masking coating) contains a microcrystalline cellulose, polyvinyl- 
pyrrolidone, colloidal silica, magnesium stearate, hypromellose, titanium dioxide, polyethylene glycol 8000 and iron oxides. Reagents used in the analysis were of HPLC grade: acetonitrile (POCH, Poland), methanol (J. T. Baker, Netherlands), ortho-phosphoric acid (Fluka, Switzerland). Candesartan cilexetil and valsartan, used as standards, were kindly donated by Polpharma (Poland). Other chemical substances and solvents necessary to prepare syrup vehicles were of pharmacopoeial quality. Xantural ${ }^{\circledR} 180$ (xanthan gum) was purchased from CP Kelco (Poland).

\section{Vehicles and pediatric syrup formulation}

Syrups with CAN and VAL were prepared in pediatric doses using three syrup vehicles, whose composition is given in Table I. Vehicle V1 was a suspending medium based on xanthan gum $(0.5 \%)$, V2 was a »vehicle for oral solution « prepared according to US Pharmacopoeia (17) and V3 was prepared from the pharmacopoeial sucrose simple syrup (17) with added sorbitol and glycerol. No preservatives were added to vehicleV3, while V1 and V2 were preserved with methylparaben and V2, additionally, with potassium sorbate. V2 was a buffered medium.

Syrups containing CAN in $1 \mathrm{mg} \mathrm{mL}^{-1}$ concentration or VAL in $4 \mathrm{mg} \mathrm{mL}^{-1}$ concentration were prepared by suspending powdered tablets in the prepared media. Tablets were crushed and powdered in a mortar, then a portion of vehicle was added to form a smooth paste. Additional vehicle was added in portions. The suspension was transferred into a glass-graduated cylinder and the rest of the vehicle was used to rinse the mortar and to make a proper volume. Each of the syrups was prepared in one batch and placed in amber glass bottles. The syrups were stored at controlled temperatures of 25 and $4{ }^{\circ} \mathrm{C}$ and protected from light. In each syrup, visual (intensity of sedimentation) and microscopic observation was performed and the $\mathrm{pH}$, viscosity, and concentration of CAN and VAL were measured periodically, every 7 days for up to 35 days.

Table I. Characteristics of syrup suspending media used in the study: composition, $p H$ and viscosity

\begin{tabular}{|c|c|c|c|}
\hline Ingredient & $\begin{array}{c}\mathrm{V} 1 \\
\%(m / m)\end{array}$ & $\begin{array}{c}\mathrm{V} 2 \\
\%(m / V)\end{array}$ & $\begin{array}{c}\mathrm{V} 3 \\
\%(\mathrm{~m} / \mathrm{m})\end{array}$ \\
\hline Xanthan gum (Xantural $\left.{ }^{\circledR} 180\right)$ & 0.50 & - & - \\
\hline Sucrose & - & 80.00 & 54.0 \\
\hline Sorbitol & 10.00 & 5.00 & 4.0 \\
\hline Glycerol & - & 5.00 & 5.0 \\
\hline Xylitol & 4.00 & - & - \\
\hline Sodium phosphate dibasic & - & 0.12 & - \\
\hline Citric acid & - & 0.20 & - \\
\hline Methylparaben & 0.20 & 0.10 & - \\
\hline Potassium sorbate & - & 0.10 & - \\
\hline Water & to 100.00 & to 100.00 & to 100.00 \\
\hline $\mathrm{pH}$ & 5.53 & 4.78 & 6.69 \\
\hline Viscosity (mPa s) & 197 & 117 & 67 \\
\hline
\end{tabular}




\section{Microscopic analysis}

Samples of each syrup were observed by means of an optical microscope (Motic BA 400, Moticam camera 2.0 MP, Germany) using total magnification of 100 and 400. Maximum particle size (length parameter) was measured for particles present in at least three different areas of observation.

\section{Intensity of sedimentation}

Each syrup was placed in a glass scale tube, achieving a $10 \mathrm{~cm}$ height of the liquid. In the course of visual observation, the character and volume of the forming sediment as well as the presence of floating particles were taken into consideration. The ease to re-disperse the precipitated particles was evaluated visually after manual shaking of the bottles with syrups where sedimentation occurred.

\section{Viscosity measurement}

Viscosity of all syrups was measured using a rotational viscometer (Viscotester E Plus - Thermo Haake, Thermo Electron Corporation, Germany). Resistance of a tested sample to torque was evaluated. Rotation speed was chosen empirically and was set at $200 \mathrm{rpm}$.

\section{Analysis of drug concentration}

Determination of CAN and VAL was performed by means of the high-performance liquid chromatography (HPLC) analysis. Previously described methods for determination of VAL $(18-20)$ and CAN $(21,22)$ in dosage forms were employed, with minor modifications. It was confirmed that the method was specific and accurate in the presence of syrup components. Isocratic separation was carried out on an Eclipse XDB - C18 (particle size $5 \mu \mathrm{m}$, $4.6 \times 150 \mathrm{~mm}$ ) using an Agilent HPLC system (Agilent Technologies 1260 Infinity, Germany). The mobile phase for CAN analysis was a mixture of phosphate buffer $\mathrm{pH} 3.0\left(0.05 \mathrm{~mol} \mathrm{~L}^{-1}\right)$, methanol and acetonitrile (30:20:50; V/V) while for VAL a mixture of phosphate buffer $\mathrm{pH}$ $2.7\left(0.065 \mathrm{~mol} \mathrm{~L}^{-1}\right)$ with acetonitrile $(55: 45 ; \mathrm{V} / \mathrm{V})$ was used. The flow rate was $1.0 \mathrm{~mL} \mathrm{~min}{ }^{-1}$. The liquid chromatograph was equipped with a UV detector set at $215 \mathrm{~nm}$ both for CAN and VAL. The injected volume for each sample was $20 \mu \mathrm{L}$. Retention times for CAN and VAL were about 13 and $5 \mathrm{~min}$, respectively. The analysis was performed at ambient temperature.

Samples for active substance analysis were withdrawn from each syrup and analyzed in triplicate. The syrups were shaken by hand, approximately for 30 seconds, and the volume of $1.0 \mathrm{~mL}$ was withdrawn and diluted to $10.0 \mathrm{~mL}$ with methanol. The solution was thoroughly shaken by hand for $1 \mathrm{~min}$ and this was followed by centrifugation (15 $\mathrm{min}, 4000$ $\mathrm{rpm}$ ). The supernatant $(1.0 \mathrm{~mL}$ ) was diluted (to $10.0 \mathrm{~mL}$ ) with a mobile phase to obtain solutions at concentrations of approximately: $10 \mu \mathrm{g} \mathrm{mL} \mathrm{L}^{-1}$ for CAN and $40 \mu \mathrm{g} \mathrm{mL} \mathrm{L}^{-1}$ for VAL, which were injected into the HPLC column $(20 \mu \mathrm{L})$.

Examples of chromatograms are presented in Figs. 1 and 2. CAN and VAL concentrations in the tested samples were calculated from standard curves obtained from the analy- 
sis of standard solutions within the concentration range of 1-20 and $10-80 \mu \mathrm{gL}^{-1}$, for CAN and VAL respectively. Linearity of the curve was confirmed by the correlation coefficient, which was greater than 0.999. Interday precision for CAN and VAL was 4.52 and $1.15 \%$, respectively (relative standard deviation).
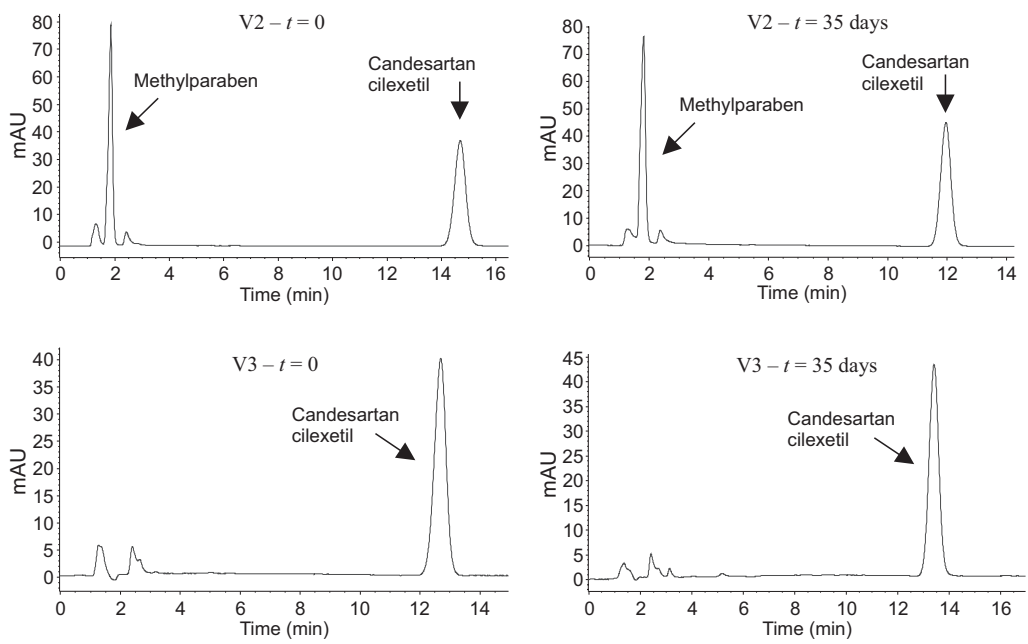

Fig. 1. Chromatograms of candesartan cilexetil syrups prepared with V2 and V3 media - analysis performed after preparation $(t=0)$ and after 35 days of storage at $25^{\circ} \mathrm{C}$.
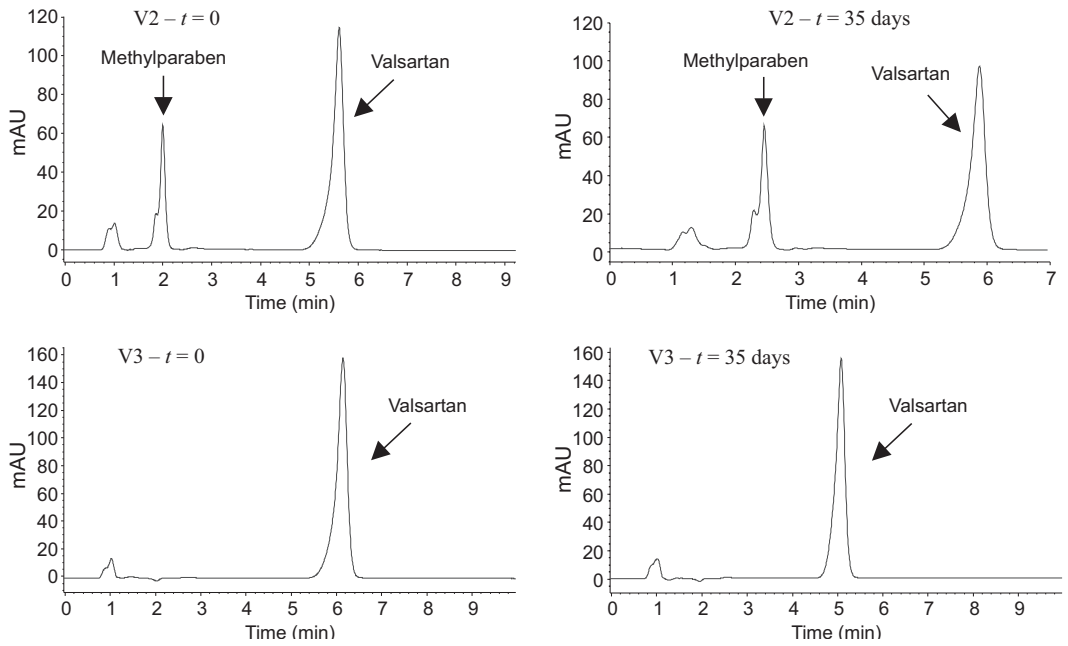

Fig. 2. Chromatograms of valsartan syrups prepared with V2 and V3 media - analysis performed after preparation $(t=0)$ and after 35 days of storage at $25^{\circ} \mathrm{C}$. 


\section{RESULTS AND DISCUSSION}

\section{Candesartan cilexetil}

All compounded CAN syrups have the same pink, milky color that comes from the tablet dye. No changes in color, odor, taste or smell were observed in syrups prepared with V2 and V3, stored at both temperatures. On the other hand, in syrups prepared with V1, an unpleasant smell and taste were detectable after 14 days of storage at both temperatures, which could indicate a microbial and/or fungal growth. Possible reason for this observation could be a decrease in the efficiency of the preservative used in the V1 medium (methylparaben) in the presence of excipients coming from the tablet, especially if some of them are insoluble and the preservative may be adsorbed on the suspended particles. Thus, methylparaben $(0.2 \%)$, the preservative used in V1, might be insufficient to ensure microbial stability of the proposed preparation. An additional preservative, like potassium sorbate used in Ora ${ }^{\circledR}$ products, could be required.

After 7 days of storage, sedimentation of the suspended particles was observed in syrups prepared with V2 and V3 vehicles at both 25 and $4{ }^{\circ} \mathrm{C}$. At the same time, the appearance of a characteristic, floating, pink layer on the surface of syrups was noted, which remained up to the end of the study. Complete separation of solid particles and the vehicle was observed after 4 weeks only in syrups prepared with V2. In spite of this, homogeneity of each syrup was easily achieved after short manual shaking. In contrast to V2 and V3 vehicles, sedimentation did not occur in syrups prepared with V1, since it was prevented by higher viscosity of the preparations (see Fig. 3A).

CAN is practically insoluble in water $(<0.01 \%)$. In the prepared syrups, CAN is present in solid state together with insoluble excipients from the tablet (corn starch, magnesium stearate, iron oxides). A slowly progressing dissolution of tablet excipients (i.e., calcium salt of carboxymethylcellulose, hydroxypropylcellulose, lactose monohydrate) occurred and was observed as an increasing haziness of the syrups. Microscopic analysis has shown that the range of particle size did not change significantly; it did not exceed $30 \mu \mathrm{m}$ in any vehicle. No aggregation of particles was observed either.
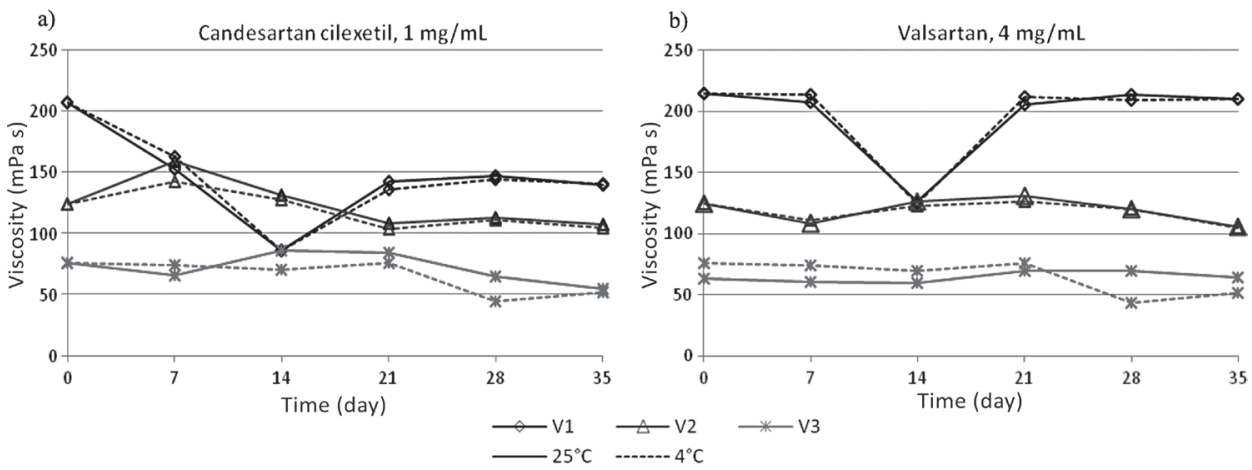

Fig. 3. Changes in viscosity of syrups with: a) candesartan cilexetil and b) valsartan prepared with V1, V2 and V3 media, stored for 35 days at 25 and $4{ }^{\circ} \mathrm{C}$. 
The initial $\mathrm{pH}$ value in the prepared media was 5.53; 4.78 and 6.69 , for V1, V2 and V3, respectively. After adding the powdered tablets to the medium, the $\mathrm{pH}$ changed only slightly and the values of 5.81, 4.65 and 6.12 were measured for syrups prepared with V1, V2 and V3 media, respectively. These changes were considered as being non-relevant for influencing CAN stability.

The $\mathrm{pH}$ of the syrups prepared with V1 or V2 did not change significantly over the stability study period at either temperature. The above mentioned organoleptic changes in the $\mathrm{V} 1$ syrup did not influence $\mathrm{pH}$ either. A small decrease in $\mathrm{pH}$ was observed at both storage temperatures in the syrup prepared with the unbuffered V3 medium (from the initial value 6.12 to around 5.66 on day 35 of the study).

Viscosity of the tested vehicles is shown in Table I. The dispersing mediumV1 is most viscous, as it contains a polymer xanthan gum. The added powdered CAN tablets $(0.81 \%$ $\mathrm{m} / \mathrm{m}$ ) practically did not influence the viscosity of vehicles, as can be seen in Fig. 3 a in comparison with the data in Table I. Rheological changes in all formulations were noted during the study period; however, the slightest viscosity difference was observed in the syrup prepared with V3 (Fig. 3a). The biggest drop in viscosity, irrespective of storage temperature, occurred during 14 days in the formulation prepared with V1 (from $207 \mathrm{mPa}$ s to 86 $\mathrm{mPa}$ ), which was followed by a further increase to $142 \mathrm{mPa}$ s and stabilization after 21 days. As mentioned above, changes in the viscosity of V1 vehicle could be related to microbial contamination. In V2 syrups, viscosity increased slightly after 7 days, but it was lower than initially after 21 days. The first observation may be explained by the slow dissolution of the tablet mass components (colloidal substances), as already mentioned above; however, further decrease in viscosity may be related to some other structural changes of the solid phase, although this has not been studied in detail. Noted changes in viscosity did not cause any problems during the administration of syrups.

To establish the expiry date for the prepared extemporaneous syrups, HPLC determination of CAN was required. The results are shown in Fig. $4 \mathrm{a}$, as the percentage of CAN compared to the initial concentration of $1 \mathrm{mg} \mathrm{mL}^{-1}$. In all syrups, no significant changes in the active substance concentration were noted during the 35 days of observation, and the range of 95-105\% of the initial concentration was not exceeded. Only in V3, the content of CAN was beyond this limit after 7 and 28 days; however, the analysis performed at these time points did not confirm the change in the drug content. No peaks from degradation products, namely candesartan and desethyl candesartan cilexetil (under the chromatography conditions expected at the retention times of $1.9 \mathrm{~min}$ and $5.2 \mathrm{~min}$ ), were observed in the chromatograms (Fig. 1).

As already mentioned in the introductory section, the suspensions prepared with Atacand $^{\circledR}$ tablets and Ora ${ }^{\circledR}$ syrups are stable for 30 days at room temperature. Our results demonstrate that the same stability can be achieved with the suspending media compounded in a pharmacy, namely pharmacopoeial medium V2 and simple medium V3.

\section{Valsartan}

All syrups prepared with VAL were cream-colored and with visible orange particles from the tablet's coat. The sweet smell and taste were unchanged in V2 and V3 syrups during storage for 35 days at 25 and $4{ }^{\circ} \mathrm{C}$. In the formulation prepared with V1, however, the 
same unpleasant smell as noted in syrup with CAN appeared after 2 weeks of storage. Due to high sugar concentration and the resulting high osmotic pressure, the unpreserved vehicle V3 did not cause any problems with microbiological stability as observed in V1 medium.

In both VAL and CAN syrups, the proportion of powdered tablet mass was similar, i.e., $0.8 \%(\mathrm{~m} / \mathrm{m})$. Sedimentation processes in VAL syrups were generally similar to those observed in CAN syrups: with phase separation, sedimentation and also some floating solids in V2 and V3 vehicles and with no sedimentation in V1 vehicle. In the less viscous V3 medium, the volume of the sediment formed was larger than in V2 medium. The sediments in syrups were downy and easily re-suspendable after short manual shaking. In all VAL syrups, a milky, moody liquid above the sediment was observed over the whole period, as opposed to CAN syrups.

Despite the different $\mathrm{pH}$ values measured in the suspending vehicles (Table I), the $\mathrm{pH}$ values of the syrups prepared with VAL were similar, ranging from 4.27 (syrup with V1) to $4.68-4.71$, indicating that tablet mass creates a buffered system. The $\mathrm{pH}$ value in all VAL syrups was not changed significantly during the study period at either temperature. Degradation of VAL in strongly acidic solutions is much faster than under alkaline conditions $(23,24)$, but less acidic solutions do not cause degradation, as can be concluded from the good stability of VAL in Ora ${ }^{\circledR}$ syrups (pH 4-5) $(7,25,26)$.

When VAL was added to the studied media as a drug substance, it did not dissolve completely even in a concentration of $1 \mathrm{~g} \mathrm{~L}^{-1}$. This is consistent with the information reported in the literature that VAL solubility in water at $25^{\circ} \mathrm{C}$ was $0.18 \mathrm{~g} \mathrm{~L}^{-1}$ and increased to $16.8 \mathrm{~g} \mathrm{~L}^{-1}$ only in a phosphate buffer at $\mathrm{pH} 8.0$ (27). This points to the conclusion that in all prepared syrups, at acidic $\mathrm{pH}, \mathrm{VAL}$ is mostly present in an insoluble form. Some other insoluble excipients derived from the tablet (microcrystalline cellulose, crospovidone, colloidal silica) remain also suspended in the syrup.

Microscopic analysis has shown that, like in CAN syrups, the range of the suspended particle size did not change significantly during storage, not exceeding $30 \mu \mathrm{m}$ in any vehicle.
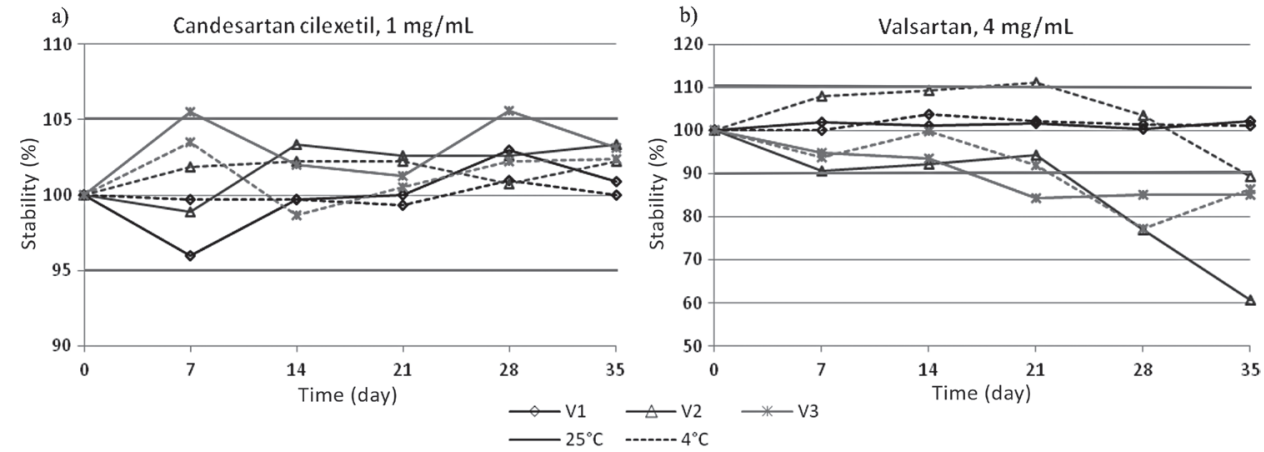

Fig. 4. Stability (\% of initial concentration) of: a) candesartan cilexetil and b) valsartan in syrups prepared with V1, V2 and V3 vehicles, stored at 25 and $4{ }^{\circ} \mathrm{C}$ for 35 days. 
As demonstrated in Fig. 3, the viscosity of all prepared syrups was the same as in those with CAN, which indicates that the suspended tablets did not significantly affect the rheology of vehicles. As in the case with CAN, the viscosity of V2 and V3 syrups with VAL was practically unchanged during storage, although V2 syrups demonstrated a slight decrease in viscosity after 7 days, while the viscosity was increased in CAN syrups at that time point. Similarly to CAN formulations, a significant drop in viscosity occurred in the V1 syrup after 2 weeks of storage. However, the values were high again after another week; thus, the behavior of this vehicle in the presence of VAL was different from CAN. A temporary decrease in viscosity of the V1 formulation may probably be explained by two independent processes - microbial growth and the interaction of xanthan gum with tablet excipients; this, however, would require further studies.

The method of preparing syrups from VAL tablets, as described and recommended by the manufacturer, relies on tablet dispersion during intensive manual agitation with a mixture of commercially available vehicles (Ora ${ }^{\circledR}$ products), while the suspension proves to be stable for 30 days at $25^{\circ} \mathrm{C}$ and 75 days at $4{ }^{\circ} \mathrm{C}(25,26)$. In all the proposed vehicles, Diovan ${ }^{\circledR}$ tablets disintegrated during stirring, so the same method of preparation, as that recommended for Ora ${ }^{\circledR}$ medium, can be proposed.

Analysis of VAL concentration has shown that the most stable syrups were prepared with vehicle V1. In those formulations, the percentage of the initial concentration was 100$103.7 \%$ throughout the whole study period (Fig. 4B). In contrast, significant changes were observed in syrups prepared with V2 and V3. A higher than $10 \%$ decrease of the initial drug content was observed in syrups prepared with V2 and V3 after 4 and 3 weeks of storage at $25^{\circ} \mathrm{C}$, respectively. At $4{ }^{\circ} \mathrm{C}$, the same result was observed one week later. This means that the recommended expiry date for VAL syrups stored at $25^{\circ} \mathrm{C}$ should be maximally 3 weeks if prepared with V2, and 2 weeks if V3 is used, because within such periods the content of the active substance was within $90-110 \%$ of the declared content. The 4-week storage for the syrup prepared with V2 can be proposed under storage conditions of $4{ }^{\circ} \mathrm{C}$. The stability data of VAL in the mixture of Ora-Sweet ${ }^{\circledR}$ and Ora-Plus ${ }^{\circledR}(1: 1)$ show that the syrup is stable for 30 days when stored at $30^{\circ} \mathrm{C}$ and stable for 75 days when stored at $2-8{ }^{\circ} \mathrm{C}$ (7). Thus, our results demonstrate that the proposed, compounded suspending media do not offer long chemical stability. However, it must be noted that long-term storage of extemporaneous, water-containing pharmaceutical preparations should be avoided and the storage time limit should not exceed 14 days, as recommended in the USP (17). This is especially important if preparations are prepared from tablets, since they are not intended as stock preparations.

\section{CONCLUSIONS}

The compounded suspending media allow the preparation of pediatric extemporaneous syrups from tablets with VAL or CAN. When V2 or V3 media were used, the stability of syrups with CAN was proven to be 35 days. VAL was less stable and due to the loss of drug content below $90 \%$ of the initial dose, only 3 or 2 week-long stability was achieved for V2 and V3 media, respectively, at $25{ }^{\circ} \mathrm{C}$, which was a shorter time than the time reported for Ora ${ }^{\circledR}$ commercial suspending media. It has to be taken into account, however, that storage time should be kept as short as possible for extemporaneous syrups, not only due to microbial stability but also due to unexpected incompatibilities, which may occur in the 
aqueous environment between the tablet's excipients and drug substance or ingredients of the syrup medium. Thus, as recommended by the USP, a 14-day expiry date is most appropriate for an aqueous compounded pharmaceutical preparation and can be achieved in V1 or V2 media for both VAL and CAN.

The suspending medium V1 is problematic due to unsatisfactory microbial stability, followed by an unpleasant odor appearing in syrups with VAL or CAN after 14 days of storage at both 25 and $4{ }^{\circ} \mathrm{C}$. However, satisfactory physical and chemical properties of the V1 syrups, such as palatability, homogeneity maintenance and proven drug assay stability, make this medium a good syrup vehicle. What remains to be considered in the follow-up studies is the change of the preservative substance in order to extend and confirm microbiological stability.

Acknowledgements. - This work was supported by the Polish Ministry of Science and Higher Education (grant N405 624638) and the quality-promoting subsidy under the Leading National Research Centre (KNOW) program 2012-2017.

\section{REFERENCES}

1. EMA/428172/2012. European Medicines Agency with its Paediatric Committee. 5-year Report to the European Commission. General report on the experience acquired as a result of the application of the Paediatric Regulation; http://ec.europa.eu/health/files/paediatrics/2012-09_pediatric_ report-annex1-2_en.pdf; access date October 28, 2014.

2. F. Brion, A. J. Nunn and A. Rieutord, Extemporaneous (magistral) preparation of oral medicines for children in European hospitals, Acta Paediatr. 92 (2003) 486-490.

3. J. Hempenstall and C. Tuleu, Formulating better medicines for children, Int. J. Pharm. 379 (2009) 143-145; DOI: 10.1016/j.ijpharm.2009.06.033.

4. Atacand (Candesartan Cilexetil) Drug Information: Description, User Reviews, Drug Side Effects, Interactions - Prescribing Information at RxList; http://www.rxlist.com/atacand-drug.htm; access date October 28, 2014.

5. Atacand. Patient Information approved by the U.S. Food and Drug Administration, 2013; http:// www1.astrazeneca-us.com/pi/Atacand.pdf; access date October 28, 2014.

6. Diovan (Valsartan) Drug Information: Description, User Reviews, Drug Side Effects, Interactions - Prescribing Information at RxList; http://www.rxlist.com/diovan-drug.htm; access date October 28, 2014.

7. Diovan. Patient Information approved by the U.S. Food and Drug Administration, 2012; http:// www.pharma.us.novartis.com/product/pi/pdf/diovan.pdf; access date October 28, 2014.

8. G. N. Darwhekar and D. K. Jain, Biopharmaceutical classification of candesartan and candesartan cilexetil, Asian J. Pharm. Life Sci. 2 (2012) 295-302.

9. J. Liu, I. R. Younis, K. R. Madabushi and P. R. Jadmav. Office of Clinical Pharmacology Review. NDA 20-838 Review - candesartan; http://www.fda.gov/downloads/drugs/developmentapprovalprocess/developmentresources/ucm189128.pdf; access date October 28, 2014.

10. M. Saydam and S. Takka, Bioavailability file: valsartan, Fabad J. Pharm. Sci. 32 (2007) 185-196.

11. P. Tosco, B. Rolando, R. Frottero, Y. Henchoz, S. Martel, P. A. Carrput and A. Gasco, Physiochemical profiling of sartans: a detailed study of ionization constants and distribution coefficients, Helv. Chim. Acta. 91 (2008) 468-482; DOI: 10.1002/hlca.200890051. 
12. F. Schaefer, J. van de Walle, A. Zurowska, C. Gimpel, K. van Hoeck, D. Drozd, G. Montini, I.V. Bagdasorova, J. Sorof, J., Sugg, R. Teng and J. W. Hainer, Efficiency, safety and pharmacokinetics of candesartan cilexetil in hypertensive children from 1 to less than 6 years of age, J. Hypertens. 28 (2010) 1083-1090; DOI: 10.1097/HJH.0b013e328336b86b.

13. F. Schaefer, R. Coppo, A. Bagga, P. Senquttuvan, R. Schlosshauer, Y. Zhang and M. Kadwa, Efficacy and safety of valsartan in hypertensive children 6 months to 5 years of age, J. Hypertens. 31 (2013) 993-1000; DOI: 10.1097/HJH.0b013e32835f5721.

14. J. Hempenstall and C. Tuleu, Meeting commentary - Formulating better medicines for children, Int. J. Pharm. 379 (2009) 143-142; DOI: 10.1016/j.ijpharm.2009.06.033.

15. Ora ${ }^{\circledR}$ Products Data Sheets; http://www.perrigo.com/business/prodsearch.aspx?group=paddock; access date October 28, 2014.

16. M. C. Nahata and V. A. Loyd, Extemporaneous drug formulations, Clin. Ther. 30 (2008) 2112-2119; DOI: 10.1016/j.clinthera.2008.11.020.

17. USP/NF 36/31. United States Pharmacopeia 2012, The United States Pharmacopeial Convention 1206, Rockville 2012, pp. 1958; 1964; 2116; 2118; 2262.

18. S. M. El-Gizawy, O. H. Abdelmageed, M. A. Omar, S. M. Deryea and A. M. Abdel-Megied, Development and validation of HPLC method for simultaneous determination of amlodipine, valsartan hydrochlorothiazide in dosage form and spiked human plasma, Am. J. Anal. Chem. 3 (2012) 422-430; DOI: 10.4236/ajac.2012.36055.

19. B. M. Sudesh and K. S. Uttamrao, Determination and validation of valsartan and its degradation products by isocratic HPLC, J. Chem. Metrl. 3 (2009) 1-12.

20. M. Pérez, G. Ramírez, M. Pérez and P. Restrepo, Validation of an analytical method for the determination of valsartan in human plasma by HPLC/UV with addition standard using losartan as an internal standard, Colomb. Med. 38 (2007) 13-20.

21. K. Hoppe, M. Sznitowska, The effect of polysorbate 20 on solubility and stability of candesartan cilexetil in dissolution media, AAPS PharmSciTech. (in press, accepted March 6, 2014).

22. G. Lunn, HPLC Methods for Recently Approved Pharmaceuticals, John Wiley \& Sons Inc., Hoboken, New Jersey, 2005, p. 104; 671.

23. S. S. Chitlange, K. Bagri and D. M. Sakarkar, Stability indicating RP- HPLC Method for simultaneous estimation of valsartan and amlodipine in capsule formulation, Asian J. Research Chem. 1 (2008) 15-18.

24. S. K. Patro, S. K. Kanungo, V. J. Patro and N. S. K. Choudhury, Stability indicating RP-HPLC method for determination of valsartan in pure and pharmaceutical formulation, E-J. Chem. 7 (2010) 246-252; DOI: 10.1155/2010/487197.

25. V. A. Loyd, Stability of extemporaneously prepared oral liquid formulations - part VI, Secundum Artem 15 (2008); http://www.perrigo.com/business/pdfs/Sec\%20Artem\%2015.1.pdf; access date October 28, 2014.

26. V. A. Loyd, Valsartan $4 \mathrm{mg} \mathrm{mL}^{-1}$ oral liquid, Int. J. Pharmac. Compd. 12 (2008) 269.

27. N. Siddiqui, A. Husain, L. Chaudhry, A. M. Shamsher, M. Mitra and P. S. Bhasin, Pharmacological and pharmaceutical profile of valsartan: a review, J. App. Pharm. Sci. 1 (2011) 12-19. 